\title{
Effects of the Membrane-covered Technology and Superphosphate on the Compost Quality and Nitrogen- containing Gas Emissions during Aerobic Composting
}

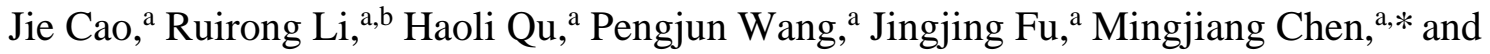 \\ Yongsheng Chen ${ }^{\mathrm{a}, *}$
}

\begin{abstract}
A lab-scale experiment was conducted to assess effects of the membranecovered technology and superphosphate on the compost quality and emissions of nitrogen-containing gases during aerobic composting. The results showed that the membrane-covered technology increased the temperature of the compost pile and accelerated degradation of organic matter. The membrane-covered (T1) sample attained a germination index (GI) of $50 \%$ and $80 \%$, approximately 2 and $9 \mathrm{~d}$ earlier, respectively, relative to the control (CK) sample. However, the application of superphosphate might have an adverse effect on the GI value. The $\mathrm{NH}_{3}$ and $\mathrm{N}_{2} \mathrm{O}$ emissions during the aerobic composting were decreased by $25.8 \%$ and $13.1 \%$, respectively, for the T1 sample compared to the CK sample, while these were reduced correspondingly by $21.3 \%$ and $27.2 \%$ for the superphosphate addition (T2) sample. Compared with the superphosphate addition, the membrane-covered approach reduced the $\mathrm{NH}_{3}$ emission but not the $\mathrm{N}_{2} \mathrm{O}$ emission. Thus, the membrane-covered aerobic composting is a potential technology for the adequate utilization of organic waste as a resource.
\end{abstract}

DOI: 10.15376/biores.17.1.1781-1793

Keywords: Membrane-covered; Compost; Gas emission; Nitrogen

Contact information: a: Ministry of Agriculture and Rural Affairs, Nanjing Institute of Agricultural Mechanization, Nanjing 210014, China; b: School of Energy and Environment, Southeast University (SEU), Nanjing 210096; *Corresponding author: cmj_cn@163.com; cys003@sina.com

\section{INTRODUCTION}

Aerobic composting is a convenient and popular method for the exploitation of organic wastes from agriculture as a resource. Products from this composting are suitable alternatives for chemical fertilizers, elevating the organic matter contents of soils, enhancing of soil's fertility (Hubbe et al. 2010), and improving the quality of crops.

Nitrogen $(\mathrm{N})$, the main component of proteins, significantly contributes to the growth of plants, including the production of fruits. In fact, it is the nutrient with the greatest impact on crop yield. However, during aerobic composting, $\mathrm{N}$ is mainly lost in the form of ammonia $\left(\mathrm{NH}_{3}\right)$ and nitrous oxide $\left(\mathrm{N}_{2} \mathrm{O}\right)$, that is not only the loss of nutrients in composting products, and these products are secondary pollutants of the environment. The nitrogen cycle is illustrated in Fig. 1.

In the process of aerobic composting, organic nitrogen decomposes and produces ammonium nitrogen by ammoniation. Ammonium nitrogen escapes easily from the composting system in the form of $\mathrm{NH}_{3}$ under high temperature $\left(65\right.$ to $\left.70{ }^{\circ} \mathrm{C}\right)$ and $\mathrm{pH}(8.4$ to 9.0) environmental conditions. $\mathrm{N}_{2} \mathrm{O}$ is mainly produced by nitrification and 
denitrification on the surface and inside the compost pile, respectively. Under the condition that the raw materials are determined, researchers mostly choose to change the nitrogen chemical process by adding exogenous substances (Jiang et al. 2016; Chen et al. 2016) to reduce $\mathrm{NH}_{3}$ and $\mathrm{N}_{2} \mathrm{O}$ emissions during aerobic composting. Therefore, additives, such as superphosphate, zeolite, woody peat, and biochar, are commonly added to reduce the loss of $\mathrm{N}$ during the composting process (Ding et al. 2019). According to Yuan et al. (2018), phosphogypsum and dicyandiamide can reduce methane $\left(\mathrm{CH}_{4}\right)$ and $\mathrm{N}_{2} \mathrm{O}$ emissions by $75.6 \%$ and $86.4 \%$, respectively; however, the $\mathrm{NH}_{3}$ emission can increase by $22.0 \%$. Jiang et al. (2014) used an aerated static box to demonstrate that superphosphate facilitates the composting process. It significantly reduced the emission of $\mathrm{NH}_{3}$ emission during the thermophilic phase, and thereby it elevated the $\mathrm{N}$ and phosphorus $(\mathrm{P})$ contents in the compost pile. Conversely, bentonite increased the emission of $\mathrm{NH}_{3}$, and thus reduced the $\mathrm{N}$ content of the compost pile. Zhang et al. (2017) indicated that although the utilization of superphosphate elevated the emission of $\mathrm{N}_{2} \mathrm{O}$, it reduced emissions of $\mathrm{CH}_{4}, \mathrm{NH}_{3}$, and $\mathrm{H}_{2} \mathrm{~S}$ by approximately $35.5 \%, 37.9 \%$, and $65.5 \%$, respectively. Overall, its application reduced the total emission of greenhouse gases by approximately $34.7 \%$. Among all additives, superphosphate has been widely used because of its low cost and the possibility of appropriately increasing the $\mathrm{P}$ content in composting products.

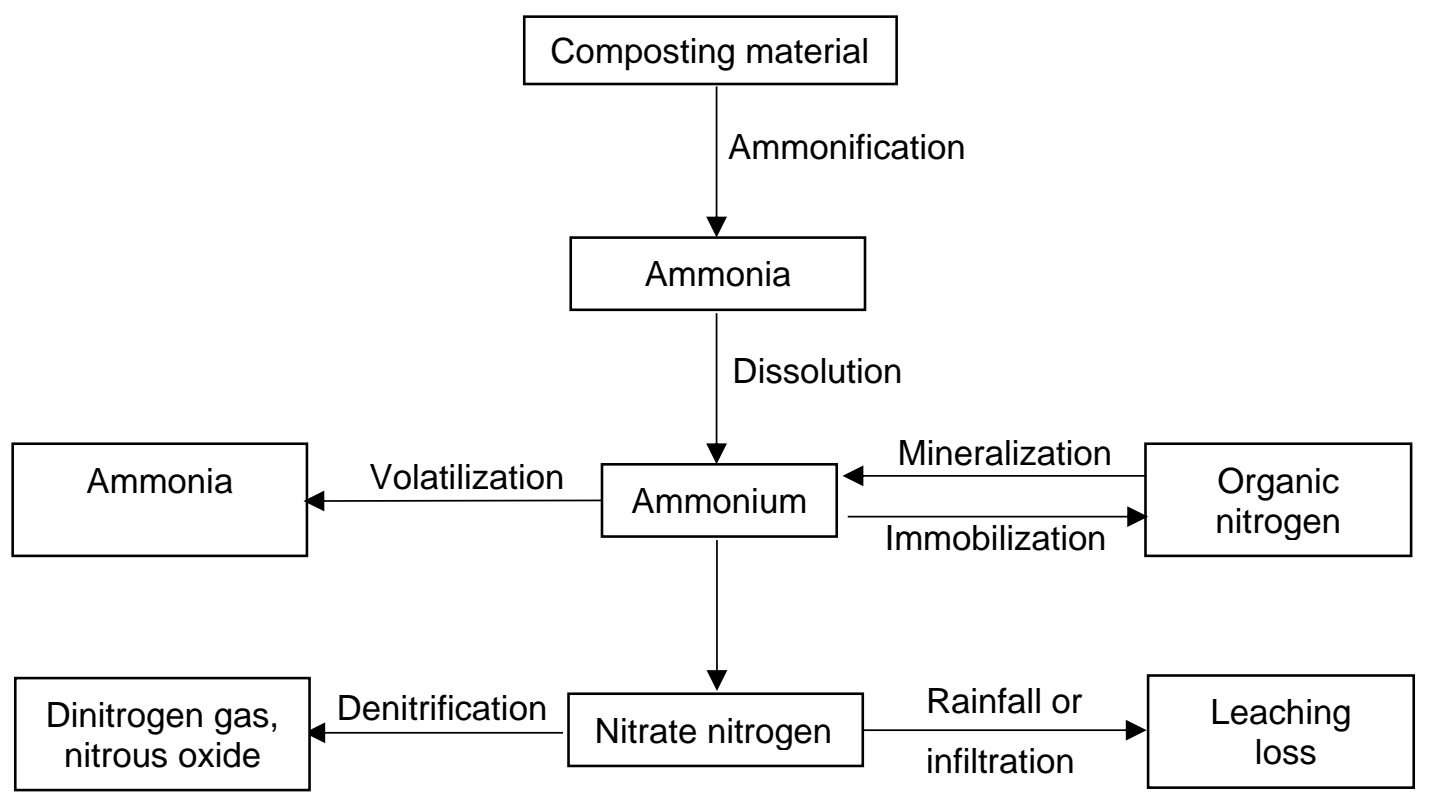

Fig. 1. Nitrogen cycle during aerobic composting

Membrane-covered aerobic composting is a technology that has gained popularity in recent years. In contrast to the traditional trough and windrow composting methods in which oxygen is supplied by mechanical turning, in the membrane-covered system, the oxygen required by aerobic microorganisms is pumped in the form of air from a pipeline beneath the compost. The molecular membrane cover is the most important component of the system. Its main structure is expanded polytetrafluoroethylene (e-PTFE), which is characterized by evenly distributed micropores. These pores can prevent the diffusion of volatile organic compounds (VOCs), bioaerosols, and dust, but permit the diffusion of small gas molecules into the atmosphere. Conversely, the water film formed through the 
condensation of water vapor on the inner side of the membrane contains dissolved gases, such as $\mathrm{NH}_{3}$, which can return to the compost pile by dripping (Ma et al. 2017). Concurrently, the molecular membrane creates a relatively stable composting environment, which is resistant to external adverse factors such as rain, wind, and ultraviolet light. Therefore, the membrane-covered composting system is suitable for open-air operation, and this can significantly reduce the costs associated with the construction of composting sites.

Owing to the high efficiency, low operation cost, and low gas emission, the membrane-covered aerobic composting technology is increasingly being studied and utilized worldwide. González et al. (2016) evaluated the composting process using an industrial-scale system and showed that the membrane-covered technology increased the temperature of the compost pile and prolonged the duration of the thermophilic phase. According to Ma et al. (2021), the molecular membrane produced by the Qingdao Zhiteng Technology Company decreased $\mathrm{N}_{2} \mathrm{O}$ and $\mathrm{CO}_{2}$ emissions by $68.4 \%$ and $1.56 \%$, respectively, and thus, it reduces the global warming potential by $53.4 \%$. Further, Li et al. (2020) demonstrated that the membrane-covered composting system decreased $\mathrm{NH}_{3}$ and $\mathrm{H}_{2} \mathrm{~S}$ emissions by $58.6 \%$ and $38.1 \%$, respectively, while the rate of loss of total $\mathrm{N}$ from the compost pile reduced by $17.3 \%$. The ammonium nitrogen and nitrate nitrogen contents of the pile also increased correspondingly by $37.7 \%$ and $11.8 \%$.

According to previous studies, both the superphosphate and membrane cover application can be expected to reduce the emission of gases during aerobic composting. However, the effects of both methods on the $\mathrm{N}$-containing gases emitted and the compost quality have rarely been reported. In addition, because of the intensive development of agriculture in China, the replacement of chemical fertilizers with organic fertilizers in the agriculture industry is desired for the protection of the rural environmental. Therefore, the utilization of organic wastes from agriculture as fertilizers is increasing in China. In the present study, stalks of the tomato plant and mushroom residues were utilized as feedstock to evaluate the effects of the membrane-covered and superphosphate approaches on parameters associated with aerobic composting including the emission of $\mathrm{NH}_{3}$ and $\mathrm{N}_{2} \mathrm{O}$. The present study highlights the potential of the membrane-covered aerobic composting technology for the utilization of agricultural wastes as fertilizers.

\section{EXPERIMENTAL}

\section{Materials}

Fresh stalks of the tomato plant and mushroom residues were collected from a vegetable park on Guli Street in Jiangsu Province, Nanjing, China. The stalks were sliced to produce straws ranging between 1 to $3 \mathrm{~cm}$ in length, and these were mixed with mushroom residues at a ratio of 4:1 (dry weight). The moisture content of the compost pile was adjusted to approximately $60 \%$ using water during the mixing, and the initial carbon to nitrogen $(\mathrm{C} / \mathrm{N})$ ratio was approximately $23: 1$. In the composting, a microbial community comprising the Bacillus licheniformis, Bacillus subtilis, Streptomyces rochei, and Aspergillus oryzae, which was produced by the Jiangsu Academy of Agricultural Sciences (Jiangsu Province, Nanjing, China) was employed, and this yielded an effective viable bacteria concentration of more than $50 \mathrm{million} / \mathrm{g}$. Data for the physicochemical properties of the compost are presented in Table 1. 
Table 1. Physicochemical Properties of the Composting Samples

\begin{tabular}{|c|c|c|c|c|}
\hline Parameters & TC (\%) & TN (\%) & C/N & MC (\%) \\
\hline Tomato stalks & $42.3 \pm 1.21$ & $1.65 \pm 0.07$ & $25.7 \pm 0.64$ & $25.7 \pm 1.34$ \\
\hline Mushroom residues & $32.4 \pm 1.45$ & $1.77 \pm 0.04$ & $17.9 \pm 0.69$ & $54.4 \pm 0.87$ \\
\hline Mixture & $39.6 \pm 0.45$ & $1.72 \pm 0.04$ & $23.1 \pm 0.25$ & $62.8 \pm 2.96$ \\
\hline
\end{tabular}

TC: Total carbon; TN: Total nitrogen; $\mathrm{C} / \mathrm{N}$ : the ratio of total carbon to total nitrogen; MC: Moisture content

\section{Experimental Design}

The aerobic composting device utilized mainly comprised a $500 \mathrm{~L}$ plastic tank with an aeration pipe at the bottom, three solid sampling ports at the top, side, and bottom, and a gas collection and sampling device at the top. The adopted molecular membrane was about $3 \mathrm{~mm}$ thick and mainly had three layers, the inner and outer layers are polyester fiber, which provided good corrosion and scratch resistance for the membrane, and the middle layer was e-PTFE. The permeability index was $0.028 \mathrm{~m}^{3} / \mathrm{min} \cdot \mathrm{m}$ at $125 \mathrm{~Pa}$. Experiments were conducted using the following groups of samples: the T1 group involving the molecular membrane covering at the top of the compost pile, the T2 group containing 5\% superphosphate (dry weight) of initial raw materials, and the control group (CK) representing the compost without the membrane covering or superphosphate application. Air was pumped into each compost pile from the bottom at a rate of $0.1 \mathrm{~m}^{3} / \mathrm{min} \mathrm{m}^{3}$ during the experiments.

\section{Sample Collection and Analysis}

Samples were collected from the upper, middle, and lower layers of the compost pile on day $0,3,9,15,21,27$, and 33 at 2 p.m. during the experiments. These samples were thoroughly mixed and divided into two subsamples. The first subsample was used to determine the $\mathrm{pH}$ and $\mathrm{EC}$ instantly, while the other subsample was stored at $-20{ }^{\circ} \mathrm{C}$ in a refrigerator for the subsequent analysis of the germination index (GI), TC, and TN. The temperature was automatically recorded once in $24 \mathrm{~h}$ using a digital thermometer, while the moisture content was measured by drying to a constant weight at $105^{\circ} \mathrm{C}$ (Tian et al. 2012). The compost samples were then mixed with deionized water at a ratio of $1: 10(\mathrm{w} / \mathrm{w})$, and the mixture was shaken for $30 \mathrm{~min}$ at the speed of $150 \mathrm{r} / \mathrm{min}$. The mixture was allowed to settle for $4 \mathrm{~h}$, and then filtered to obtain the supernatant that was employed for measurement of the $\mathrm{pH}$ and EC by a detector (FE28, Mettler-Toledo, Shanghai, China) (Wang et al. 2015). Ten Chinese cabbage seeds were distributed on filter paper in Petri dishes and moistened with $5 \mathrm{~mL}$ of the compost water extract. Incubation was performed at $25 \pm 2{ }^{\circ} \mathrm{C}$ for $48 \mathrm{~h}$, and the GI was calculated based on the seed germination rate and root length. For the CK samples, distilled water instead of the compost water extract was used. The GI was calculated as follows:

$$
\mathrm{GI}=\frac{\text { seed germination of the treatment }(\%) \times \text { root length of the treatment }(\mathrm{mm})}{\text { seed germination of the control }(\%) \times \text { root length of the control }(\mathrm{mm})} \times 100
$$

The error associated with the ruler used to measure the root length was less than 1 $\mathrm{mm}$. Gas samples were collected using an interval of two days during the duration of the experiment, the concentrations of $\mathrm{NH}_{3}$ and $\mathrm{N}_{2} \mathrm{O}$ were determined correspondingly using a detection tube (GASTEC, Kanagawa, Japan) and a gas chromatograph (Agilent Technologies, Santa Clara, CA, USA). 


\section{Data and Statistical Analyses}

Excel 2016 (Microsoft Corp, Redmond, WA, USA) and SPSS 22 (IBM, Armonk, $\mathrm{NY}$, USA) were utilized for all statistical analyses. All parameter measurements (temperature, $\mathrm{pH}, \mathrm{EC}, \mathrm{GI}, \mathrm{NH}_{3}$ and $\mathrm{N}_{2} \mathrm{O}$ ) were performed in triplicates for the same sample. One-way analysis of variance (ANOVA) was used to analyze the data. When an ANOVA result was significant, the means were compared with Fisher's protected least significant difference test at $\mathrm{p} \leqslant 0.05$. Prior to the ANOVA, the normality of distribution and homogeneity of variance were checked with Shapiro-Wilk and Levene's test, respectively. Plots were generated using OriginPro 9.1 software (OriginLab, Northampton, MA, USA).

\section{RESULTS AND DISCUSSION}

\section{Changes in Physicochemical Parameters of Composting Samples}

Changes in temperature

Temperature is an important parameter in the aerobic composting process, and thus, it is employed to characterize the process into the warming, thermophilic, and cooling phases. To eliminate the impacts of insect eggs, pathogens, and other harmful organisms in the compost material, the thermophilic phase is generally required to attain a temperature of at least $50{ }^{\circ} \mathrm{C}$ and last between 4 to 5 days (Li et al. 2018).

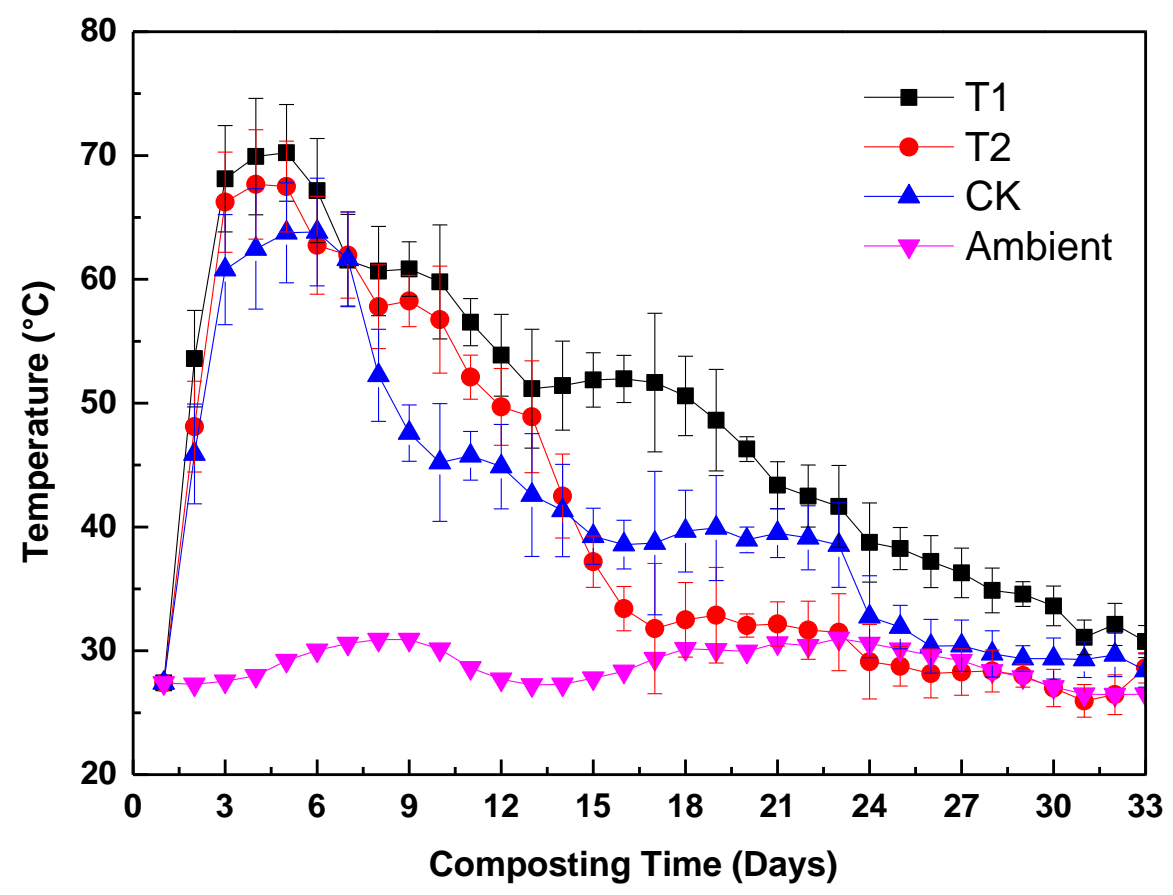

Fig. 2. Plots showing changes in temperature during the composting of three groups

The changes in temperature during the composting of different groups displayed in Fig. 2 are typical of aerobic composting. The temperatures of the T1, T2, and CK groups increased rapidly during the first two days, and reached maximum temperatures of 70.2, 67.7 , and $63.8{ }^{\circ} \mathrm{C}$, respectively, on $4^{\text {th }}, 3^{\text {rd }}$, and $4^{\text {th }}$ day, respectively. The increase in 
temperature in the compost was attributed to heat generated by microorganisms using $\mathrm{C}$ and $\mathrm{N}$ sources. Figure 1 also reveals that the thermophilic phase of the T1 group lasted significantly longer than those of the T2 and CK groups, and this highlights the superiority of the membrane-covered approach for elevating and preserving the composting temperature, which is consistent with the conclusion of Ma et al. (2017). During the initial $15 \mathrm{~d}$, the temperatures of the T2 group also significantly surpassed those of the CK sample, and this difference was attributed to the utilization by microorganisms of the high $\mathrm{P}$ and trace elements from the superphosphate.

\section{pH Variations}

According to previous studies, the release of $\mathrm{NH}_{3}$ during the composting process is strongly correlated with the $\mathrm{pH}$ of the compost (Li et al. 2008; Zhu et al. 2017). This is mainly because the accumulation of ammonium nitrogen and the increase in the concentration of $\mathrm{NH}_{3}$ in a compost elevates the associated $\mathrm{pH}$ value. Concurrently, the high $\mathrm{pH}$ value enhances the release of $\mathrm{NH}_{3}$ to the environment.

(a)

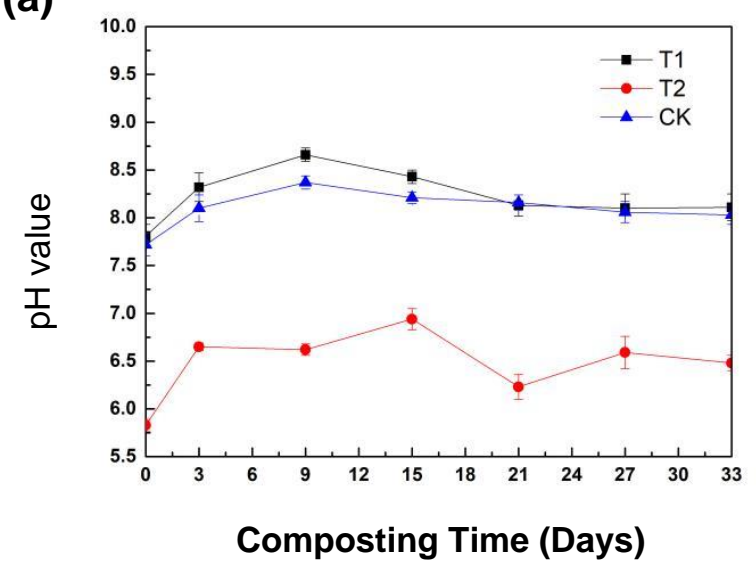

(b)

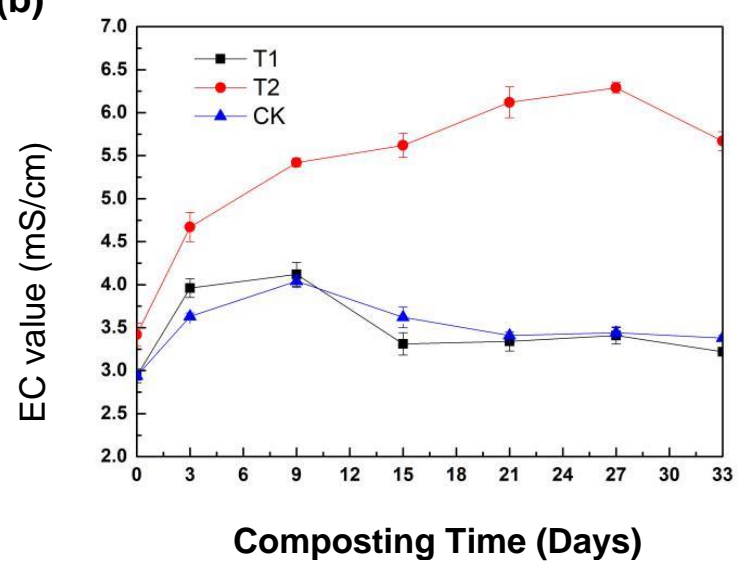

Fig. 3. Plots showing changes in the (a) pH and (b) EC value during the composting of three types of samples

As shown in Fig. 3a, the $\mathrm{pH}$ values for the types of samples initially increased and subsequently decreased. During the experiments, the T1, T2, and CK samples attained maximum $\mathrm{pH}$ values of $8.7,8.4$, and 6.9 , respectively. The production of $\mathrm{NH}_{3}$ and the degradation of acids mainly accounted for the increasing $\mathrm{pH}$ during the early stage for all sample types (Jia et al. 2016). Most of the $\mathrm{NH}_{4}{ }^{+}-\mathrm{N}$ was converted by nitrification, while short chain organic acids produced from the degradation of organic matter likely decreased the $\mathrm{pH}$ value of the samples during a later stage (Zhou et al. 2019). The higher $\mathrm{pH}$ value of the T1 sample relative to that of the CK sample might have been because the water film on the inner side of the membrane dissolved part of $\mathrm{NH}_{3}$, which dropped back into the compost pile. The $\mathrm{NH}_{3}$ became alkaline after dissolving in water, which might have led to the increased $\mathrm{pH}$ value. Among the three types of samples, the T2 displayed the lowest $\mathrm{pH}$ value because the superphosphate was acidic, and its $\mathrm{pH}$ value was about 3.0. Nevertheless, the final $\mathrm{pH}$ value of the $\mathrm{T} 1, \mathrm{~T} 2$, and $\mathrm{CK}$ samples were 8.11, 8.03, and 6.48, respectively, and these were consistent with the $\mathrm{pH}$ values required for organic fertilizers. 


\section{EC Changes}

The electrical conductivity (EC) value reflects the salinity of soluble components from the compost, and a high salinity can damage plants through osmotic pressure (Huang et al. 2004). The changes in the EC value during the experiments for the three types of samples are exhibited in Fig. 3b. The EC value for the T1 and CK samples increased during the initial $9 \mathrm{~d}$ and decreased subsequently. The release of soluble mineral salts, such as ammonium ions and phosphate, caused by the rapid mineralization of organic matter might be the reason the EC value increased in the initial stage. Then, due to the production of $\mathrm{NH}_{3}$ and the precipitation of mineral salts, the EC value decreased gradually and stabilized in the following time. The maximum EC values for the T1 and CK samples were 4.12 and $4.04 \mathrm{mS} \mathrm{cm}^{-1}$, respectively, while the final values were correspondingly 3.22 and $3.38 \mathrm{mS}$ $\mathrm{cm}^{-1}$. The significantly higher final EC value for the T2 sample relative to those for the T1 and $\mathrm{CK}$ samples was mainly linked to the calcium dihydrogen phosphate, free phosphoric acid, and sulfuric acid in the superphosphate. Calcium dihydrogen phosphate contained inorganic salts, and the presence of free phosphoric acid and sulfuric acid accelerated the dissolution of inorganic salts, which led to an increased EC value. In fact, the final EC value of $5.67 \mathrm{mS} \mathrm{cm}^{-1}$ for the T2 sample exceeded the safety threshold for plants of 4.0 $\mathrm{mS} \mathrm{cm} \mathrm{cm}^{-1}$ ( $\mathrm{Li}$ et al. 2007). This may have been the reason for the low GI value in T2. According to the Fig. 3b, the EC value showed a downward trend at the end of the composting period, which might be caused by the biodegradation of water-soluble substances, such as organic acids, during this period (Hosseini and Aziz 2013).

\section{GI Characterization}

The GI is a vital parameter associated with the aerobic composting process. It can be employed to evaluate the stability and risk of products from composting (Zucconi 1981). If the GI of a composting product attains $50 \%$, the product is characterized as phytotoxicity-free, whereas if the GI exceeds $80 \%$, the product is considered mature (Saidi et al. 2009). The changes in the GI of the three types of samples are shown in Fig. 4.

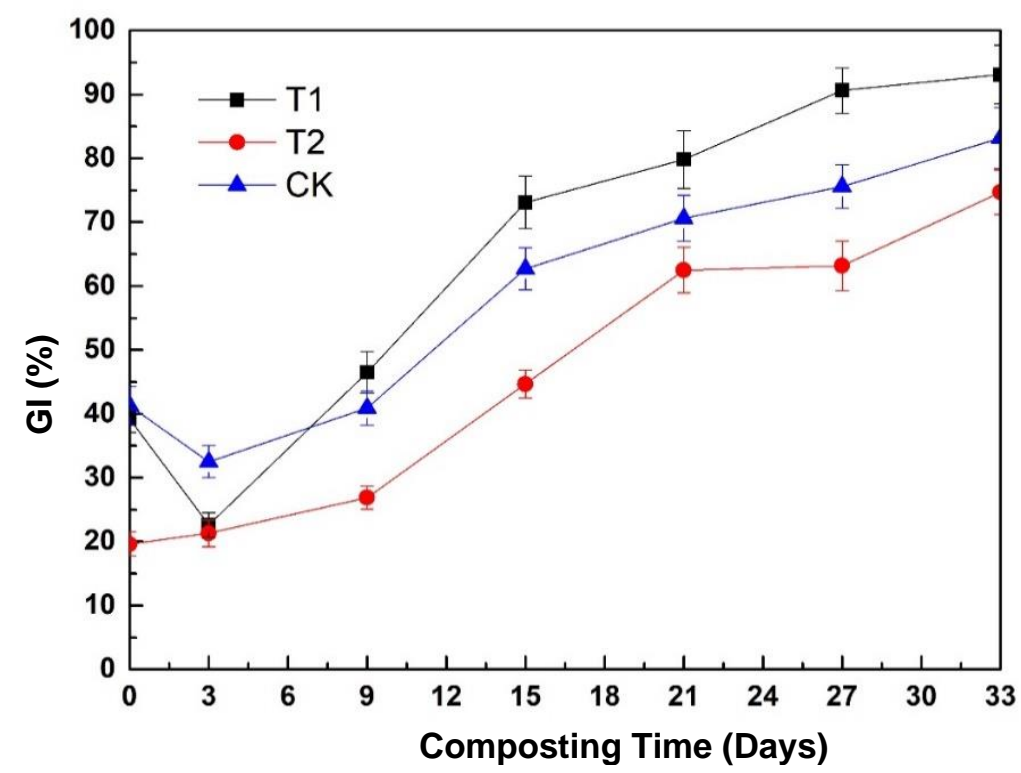

Fig. 4. Plot showing changes in the Gl during composting of three types of samples 
The GI of the T1 and CK samples decreased slightly during the initial stage, and then they increased gradually until the end of the respective composting experiments. The decrease in the GI during the initial stage was likely because of rapid degradation of organic matter, which probably generated substances that were unfavorable for the germination of the seeds. The final GI of the T1 and CK samples were correspondingly $93.1 \%$ and $83.2 \%$, and both values satisfied the maturity requirement. However, compared with the CK sample, the T1 sample attained a GI of 50\% and $80 \%$ approximately 2 and $9 \mathrm{~d}$ earlier, respectively.

These results indicate that the membrane-covered technology can enhance the speed of the composting process, and thus shorten the composting cycle. The increased speed was linked to the temperature enhancement of the compost using the membranecovered technology, which accelerated the degradation of organic matter. Although the GI of the T2 sample increased continuously, these values were lower compared to those of the T1 and CK sample during an identical period. The final GI of $74.7 \%$ for the T2 sample was probably because of the free acids and high salinity from the superphosphate (Jiang et al. 2014; Yang et al. 2015). According to the trends in Fig. 3, a longer composting time is probably required to enhance the GI of the T2 sample. However, Yang et al. (2015) reported that although the superphosphate can decrease the degradation of organic matter in compost, no adverse effect on the maturity and GI of the compost products was observed. These observations were probably because the study involved a longer composting time.

\section{Nitrogen-containing Gases Emissions from the Aerobic Composting} $\mathrm{NH}_{3}$ emission characterization

The emission of $\mathrm{NH}_{3}$ accounts for more than $75 \%$ of the total $\mathrm{N}$ loss during aerobic composting (Jiang et al. 2013). The $\mathrm{NH}_{3}$ emission rates and cumulative emissions for the three groups are shown in Fig. 5. Evidently, the production and emission of $\mathrm{NH}_{3}$ are strongly correlated with the composting temperature $(\mathrm{p}<0.001)$. The three groups exhibited sharp rises, followed by gradual declines. The $\mathrm{NH}_{3}$ emissions for all groups in the present study occurred mainly in the initial $18 \mathrm{~d}$ of composting. This was associated with the rapid temperature increase, the high-temperature fermentation, and the rapid mineralization of organic $\mathrm{N}$ in the compost during this stage of the experiments. Then due to the depletion of organic matter and the reduction of ammonification bacteria activity, $\mathrm{NH}_{3}$ emission decreased in the subsequent time.

Fukumoto et al. (2011) indicated that the $\mathrm{NH}_{3}$ emitted during aerobic composting mainly associated with the thermophilic phase, followed by a gradual decline in the next stage, which was consistent with the results obtained in the present study. The total $\mathrm{NH}_{3}$ emitted from the T1 was $25.8 \%$ less than that from the CK group, and this indicated that the membrane-covered approach reduced $\mathrm{NH}_{3}$ emission during anaerobic composting. This decrease was attributed to the condensed water vapor on the internal surface of the membrane, which allows dissolved $\mathrm{NH}_{3}$ to return to the compost because of the force of gravity (Ma et al. 2017, 2021). The total $\mathrm{NH}_{3}$ emitted from the $\mathrm{T} 2$ was $21.3 \%$ less than that of the CK group, and this was mainly because the superphosphate utilized decreased the $\mathrm{pH}$ value of the compost pile, and this acidic environment then reduced the emission of $\mathrm{NH}_{3}$. 


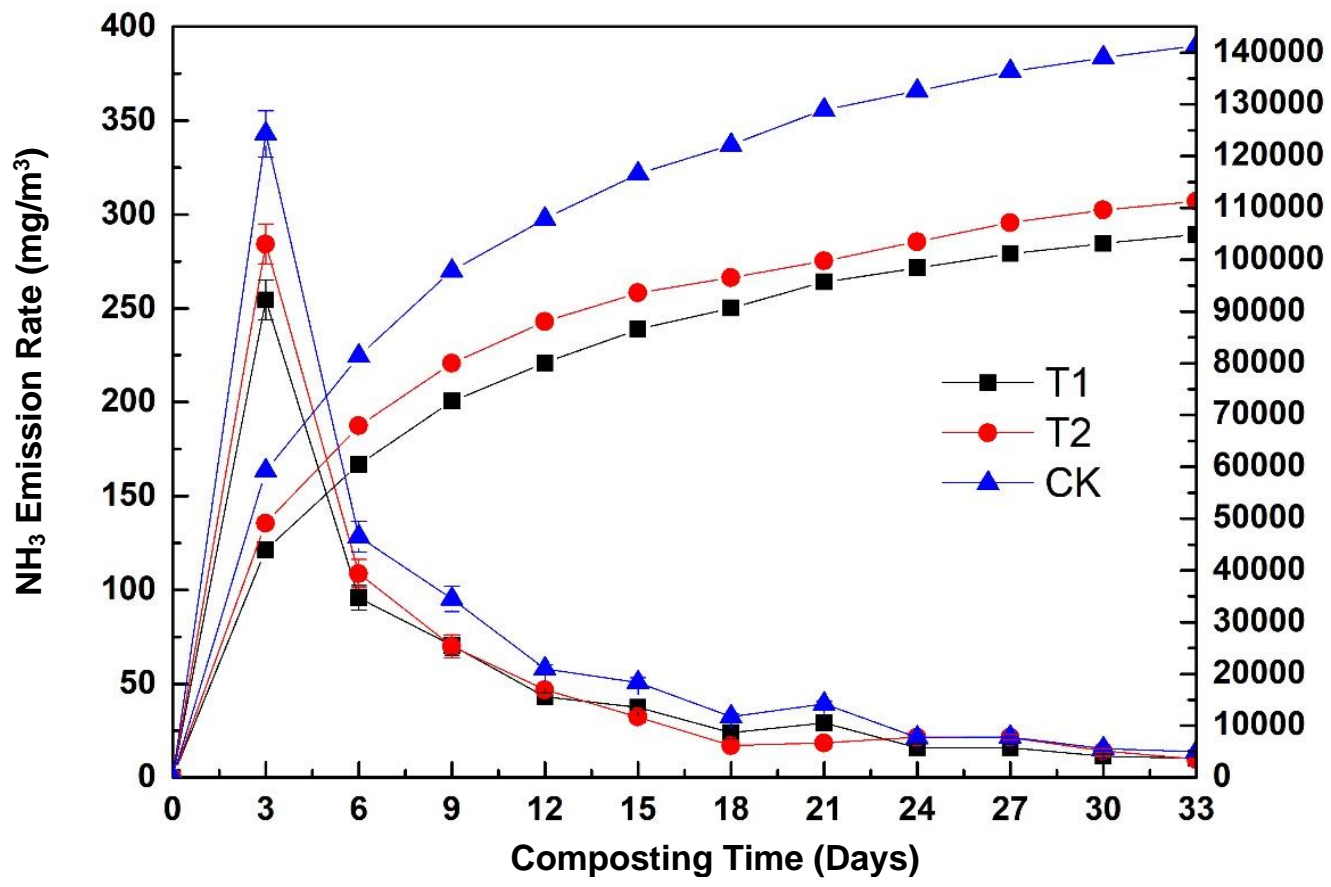

Fig. 5. Plots displaying the emission rate and the cumulative emission of $\mathrm{NH}_{3}$ during composting of three groups

\section{$\mathrm{N}_{2} \mathrm{O}$ Emission Characterization}

The chemical compound $\mathrm{N}_{2} \mathrm{O}$ is an atmospheric pollutant that damages the ozonosphere and enhances the greenhouse effect, and its warming potential is 298 times higher than that of $\mathrm{CO}_{2}$. The production of $\mathrm{N}_{2} \mathrm{O}$ in compost is mainly associated with the nitrification of $\mathrm{NH}_{4}{ }^{+}-\mathrm{N}$ and the incomplete denitrification of $\mathrm{NO}^{-}-\mathrm{N}$ (Huang et al. 2004). The $\mathrm{N}_{2} \mathrm{O}$ emission rates and cumulative emissions for the three groups are shown in Fig. 6.

The trends of a rapid rise followed a gradual decrease displayed by the three groups were broadly consistent with those for the emission of $\mathrm{NH}_{3}$. The $\mathrm{N}_{2} \mathrm{O}$ emissions for all groups in the present study mainly occurred in the initial $12 \mathrm{~d}$ of composting. This observation was probably because of the rapid oxidation of organic $\mathrm{N}$ and $\mathrm{NH}_{4}{ }^{+}$promoting the emission of $\mathrm{N}_{2} \mathrm{O}$, which is consistent with the conclusion of Stange and Neue (2009). However, some studies have pointed out that neither nitrifier nor denitrifier can adapt to the high-temperature environment of compost, so $\mathrm{N}_{2} \mathrm{O}$ could not be produced in the thermophilic phases. According to some previous studies (Bian et al. 2017; Ma et al. 2021), the maximum $\mathrm{N}_{2} \mathrm{O}$ emission rates were observed during the intermediate stage of composting when the temperature had decreased. The $\mathrm{NO}_{2}^{-}$accumulation was considered the main reason for this phenomenon. The total $\mathrm{N}_{2} \mathrm{O}$ emissions of the $\mathrm{T} 1$ and $\mathrm{T} 2$ groups were $13.1 \%$ and $27.2 \%$, respectively, less than that of the CK group. This indicated that the membrane-covered approach can reduce the emission of $\mathrm{N}_{2} \mathrm{O}$, but the performance was inferior to that of the $5 \%$ superphosphate addition. 


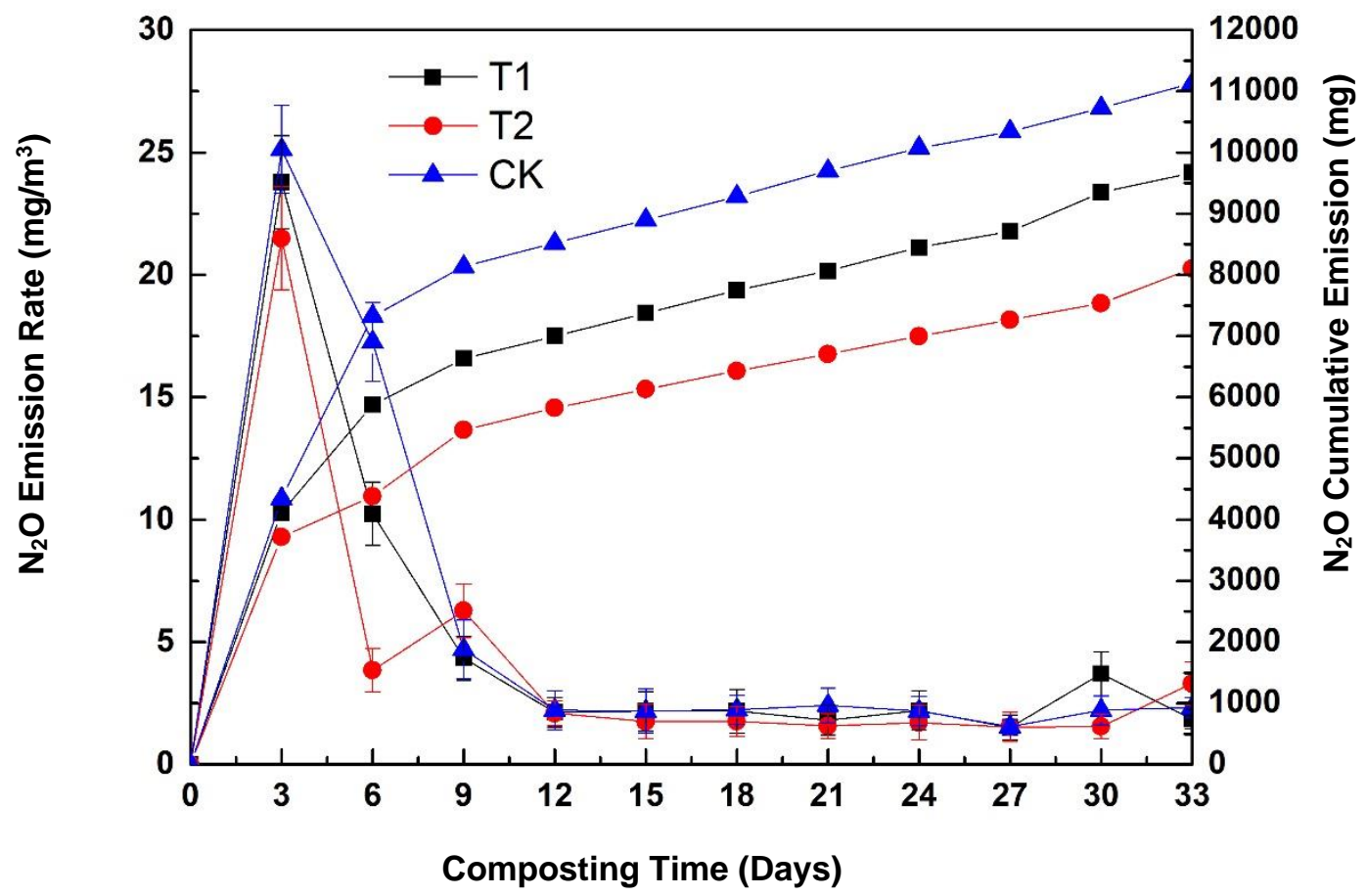

Fig. 6. Plot showing the emission rates and cumulative emissions of $\mathrm{N}_{2} \mathrm{O}$ during composting of the three groups

\section{CONCLUSIONS}

1. The present study demonstrated that the membrane-covered technology improved the temperature and the germination index (GI) value of compost. Conversely, the application of 5\% superphosphate in the process might have an adverse effect on the GI value.

2. Membrane-covered technology accelerated the composting process. The product was characterized as phytotoxicity-free and mature approximately 2 and $9 \mathrm{~d}$ earlier, respectively, compared with the control (CK) group samples.

3. Both the membrane-covered and 5\% superphosphate application reduced emissions of $\mathrm{NH}_{3}$ and $\mathrm{N}_{2} \mathrm{O}$ during the composting process. However, the membrane-covered technology exhibited superiority for the reduction of $\mathrm{NH}_{3}$ emission, while the superphosphate application was better for the reduction of $\mathrm{N}_{2} \mathrm{O}$ emission. Compared with the CK group samples, the membrane-covered technology reduced $\mathrm{NH}_{3}$ and $\mathrm{N}_{2} \mathrm{O}$ correspondingly by $25.8 \%$ and $13.1 \%$, while the $5 \%$ superphosphate application decreased the $\mathrm{NH}_{3}$ and $\mathrm{N}_{2} \mathrm{O}$ emissions by $21.3 \%$ and $27.2 \%$, respectively. 


\section{ACKNOWLEDGMENTS}

This work was supported by the Fundamental Research Funds for the Central Public-interest Scientific Institution Basal Research Fund (Grant No. S202004-02), the Agricultural Science and Technology Innovation Program (CAAS-NIAM-SJ-201901), and the Key Research and Development Program of Hebei Province (Grant No. 20327313D).

\section{REFERENCES CITED}

Bian, R., Sun, Y., Li, W., Ma, Q., and Chai, X. (2017). “Co-composting of municipal solid waste mixed with matured sewage sludge: The relationship between $\mathrm{N}_{2} \mathrm{O}$ emissions and denitrifying gene abundance," Chemosphere 189, 581-589. DOI: 10.1016/j.chemosphere.2017.09.070

Chen, Y., Huang, A., Li, Y., Huang, J., Zhang J., Zhang J., and Tan, X. (2016). "Effect of nitrification inhibitor on physico-chemical properties and denitrification functional genes during agricultural waste composting," Chinese Journal of Environmental Engineering 8(10), 4451-4456. DOI 10.12030 /j.cjee.201503136

Fukumoto, Y., Suzuki, K., Kuroda, K., Waki, M., and Yasuda, T. (2011). "Effects of struvite formation and nitratation promotion on nitrogenous emissions such as $\mathrm{NH}_{3}$, $\mathrm{N}_{2} \mathrm{O}$ and NO during swine manure composting," Bioresource Technology 102(2), 1468-1474. DOI: 10.1016/j.biortech.2010.09.089

González, I., Robledo-Mahón, T., Silva-Castro, G. A., Rodríguez-Calvo, A., Gutiérrez, M. C., Martín, M. Á., Chica, A. F., and Calvo, C. (2016). "Evolution of the composting process with semi-permeable film technology at industrial scale," Journal of Cleaner Production 115, 245-254. DOI: 10.1016/j.jclepro.2015.12.033

Huang, G. F., Wong, J. W. C., Wu, Q. T., and Nagar, B. B. (2004). "Effect of C/N on composting of pig manure with sawdust," Waste Management 24(8), 805-813. DOI: 10.1016/j.wasman.2004.03.011

Hubbe, M., Nazhad, M., and Sanchez, C. (2010). "Composting as a way to convert cellulosic biomass and organic waste into high-value soil amendments: A review," BioResources 5(4), 2808-2854. DOI: 10.15376/biores.5.4.2808-2854

Hosseini, S. M.and Aziz, H. A. (2013). "Evaluation of thermochemical pretreatment and continuous thermophilic condition in rice straw composting process enhancement," Bioresource Technology 133, 240-247. DOI: 10.1016/j.biortech.2013.01.098.

Jia, X., Wang, M., Yuan, W., Ju, X., and Yang, B. (2016). "The influence of biochar addition on chicken manure composting and associated methane and carbon dioxide emissions," BioResources 11(2), 5255-5264. DOI: 10.15376/biores.11.2.5255-5264

Jiang, J., Huang, Y., Liu, X., and Huang, H. (2014). "The effects of apple pomace, bentonite and calcium superphosphate on swine manure aerobic composting," Waste Management 34(9), 1595-1602. DOI: 10.1016/j.wasman.2014.05.002

Jiang, T., Schuchardt, F., Li, G. X., Guo, R., and Luo, Y. M. (2013). "Gaseous emission during the composting of pig feces from Chinese Ganqinfen system," Chemosphere 90(4), 1545-1551. DOI: 10.1016/j.chemosphere.2012.08.056

Jiang, T., Ma, X., Tang, Q., Yang, J., Li, G.and Schuchardt, F. (2016). "Combined use of nitrification inhibitor and struvite crystallization to reduce the $\mathrm{NH}_{3}$ and $\mathrm{N}_{2} \mathrm{O}$ emissions during composting," Bioresource Technology 217, 210-218. DOI: 10.1016/j.biortech.2016.01.089 
Li, C., Li, G., Li, Y., Li, Y., and Pan, L. (2007). "Fuzzy mathematics-based evaluation of municipal solid waste compost maturities in different spaces in static tunnel from Nangong Compost Plant," Transactions of the Chinese Society of Agricultural Engineering (23)2, 201-206. DOI: 10.3321/j.issn:1002-6819.2007.02.039

Li, B., Wang, C., Jiang, L., Li, H., Yang, J., and Yang, B. (2008). "Inhibitory effect of auxiliary organic materials on ammonia volatilization in composting and the influencing factors," Plant Nutrition and Fertilizer Science 14(5), 987-993.

Li, X., Lu, M., Shi, X., Xu, X., and Guo, R. (2018). “Accelerating organic matter degradation and reducing $\mathrm{NH}_{3}$ emission during constant high temperature composting of cattle manure and corn straw with addition of porous material," Transactions of the Chinese Society of Agricultural Engineering 34(S1), 132-137. DOI: 10.11975/j.issn.1002-6819.2018.z.020

Li, Y., Liu, Y., Yong, X., Wu, X., Jia, H., Wong, J. W. C., Wu, H., and Zhou, J. (2020). "Odor emission and microbial community succession during biogas residue composting covered with a molecular membrane," Bioresource Technology 297, article ID 122518. DOI: 10.1016/j.biortech.2019.122518

Ma, S. S., Sun, X. X., Han, N. J., Li, R. Q., Schlick, U. W. E., and Huang, G. Q. (2017). "Reduction of ammonia emission during membrane-covered aerobic composting," Transactions of The Chinese Society of Agricultural Machinery 48(11), 344-349. DOI: 10.6041/j.issn.1000-1298.2017.11.042

Ma, S., Xiong, J., Wu, X., Liu, H., Han, L., and Huang, G. (2021). "Effects of the functional membrane covering on the gas emissions and bacterial community during aerobic composting," Bioresource Technology 340, Article ID 125660. DOI: 10.1016/j.biortech.2021.125660

Saidi, N., Kouki, S., M'Hiri, F., Jedidi, N., Mahrouk, M., Hassen, A., and Ouzari, H. (2009). "Microbiological parameters and maturity degree during composting of Posidonia oceanica residues mixed with vegetable wastes in semi-arid pedo-climatic condition," Journal of Environmental Sciences 21(10), 1452-1458. DOI: 10.1016/s1001-0742(08)62439-0

Stange, C. F., and Neue, H. (2009). "Measuring and modelling seasonal variation of gross nitrification rates in response to long-term fertilisation," Biogeosciences 6(10), 21812192. DOI: $10.5194 / \mathrm{bg}-6-2181-2009$

Tian, W., Li, L., Liu, F., Zhang, Z., Yu, G., Shen, Q., and Shen, B. (2012). “Assessment of the maturity and biological parameters of compost produced from dairy manure and rice chaff by excitation-emission matrix fluorescence spectroscopy," Bioresource Technology 110, 330-337. DOI: 10.1016/j.biortech.2012.01.067

Wang, X., Cui, H., Shi, J., Zhao, X., Zhao, Y., and Wei, Z. (2015). "Relationship between bacterial diversity and environmental parameters during composting of different raw materials," Bioresource Technology 198, 395-402. DOI:

10.1016/j.biortech.2015.09.041

Yang, F., Li, G., Shi, H., and Wang, Y. (2015). "Effects of phosphogypsum and superphosphate on compost maturity and gaseous emissions during kitchen waste composting," Waste Management 36, 70-76. DOI: 10.1016/j.wasman.2014.11.012

Yuan, J., Li, Y., Chen, S., Li, D., Tang, H., Chadwick, D., Li, S., Li, W., and Li, G. (2018). "Effects of phosphogypsum, superphosphate, and dicyandiamide on gaseous emission and compost quality during sewage sludge composting," Bioresource Technology 270, 368-376. DOI: 10.1016/j.biortech.2018.09.023

Zhang, D., Luo, W., Yuan, J., Li, G., and Luo, Y. (2017). "Effects of woody peat and 
superphosphate on compost maturity and gaseous emissions during pig manure composting," Waste Management 68, 56-63. DOI: 10.1016/j.wasman.2017.05.042

Zhou, G., Qiu, X., Chen, L., Zhang, C., Ma, D., and Zhang, J. (2019). "Succession of organics metabolic function of bacterial community in response to addition of earthworm casts and zeolite in maize straw composting," Bioresource Technology 280, 229-238. DOI: 10.1016/j.biortech.2019.02.015

Zhu, X., Dong, W., Wang, H., Yang, C., Liu, H., and Liu, E. (2017). "Effects of cattle manure composting methods on greenhouse gas and ammonia emissions,"

Transactions of the Chinese Society of Agricultural Engineering 33(10), 258-264. DOI. 10.11975/j.issn.1002-6819.2017.10.034

Article submitted: November 16, 2021; Peer review completed: December 19, 2021; Revised version received: January 17, 2022; Accepted: January 20, 2022; Published: January 25, 2022.

DOI: $10.15376 /$ biores.17.1.1781-1793 